\title{
Impact of Corrosive Liquid on Trivalent Chromium over Aluminium Alloys
}

\author{
Kalaivanan Thirupathi ${ }^{*}$, Pál Bárczy², Béla Márton Somosvári ${ }^{3}$ \\ ${ }^{1}$ Institute of Ceramics and Polymer Engineering, University of Miskolc, Miskolc, Hungary \\ ${ }^{2}$ Matmod Ltd., Miskolc, Hungary \\ ${ }^{3}$ Admatis Ltd., Miskolc, Hungary \\ Email: *kalai.vanan@matmod.eu
}

How to cite this paper: Thirupathi, K. Bárczy, P. and Somosvári, B.M. (2017) Impact of Corrosive Liquid on Trivalent Chromium over Aluminium Alloys. Journal of Surface Engineered Materials and Advanced Technology, 7, 51-60. https://doi.org/10.4236/jsemat.2017.73005

Received: May 12, 2017

Accepted: July 2, 2017

Published: July 5, 2017

Copyright (๑) 2017 by authors and Scientific Research Publishing Inc. This work is licensed under the Creative Commons Attribution International License (CC BY 4.0).

http://creativecommons.org/licenses/by/4.0/

cc) (i) Open Access

\begin{abstract}
Considering aviation and space sectors, aluminium alloys are commonly used due to its excellent mechanical and physical properties. Though satellite hardware is confined to controlled environment, it requires anticorrosive treatment over metal substrate followed by a systematic coating scheme. The trivalent chromium coating was deposited over three aluminium alloys namely AA6063, AA7075 and AA6082. The variation in corrosion resistance property of trivalent chromium over each aluminium alloy has been studied in detail. The Neutral Salt Spray (NSS) test result shows that trivalent chromium coating over AA7075 alloy is affected by pitting corrosion compared to other two alloys. In addition to that, NSS test also proves that thickness of the layer does not have any influence corrosion resistance property of trivalent chromium coating. Furthermore, ions in trivalent chromium coating was identified using Secondary Neutral Mass Spectroscopy (SNMS) and degradation of coating in a corrosive liquid studied using Inductively Coupled Plasma Optical Emission Spectroscopy (ICP-OES) instrument to understand mechanism of corrosion. The results indicated that both coating and substrate is involved in corrosion process. The number of elements dissolved in to salt solution reveals the weak ionic bonding of coating towards substrates. In comparison, AA7075 alloy has weaker bonding than AA6082 and AA6063 series. The alloying elements such as zinc and copper are removed from substrate by corrosive solution.
\end{abstract}

\section{Keywords}

Trivalent Chromium, Chromate Conversion Coating, ASTM B117, Neutral Salt Spray Test

\section{Introduction}

Aluminium alloys are commonly used material in aviation and aerospace indus- 
tries due to its lightweight and high strength in nature [1]. AA7075, AA6063 and AA6082 alloys are widely used for space sectors. Chromate conversion coating technique is used for passivating these aluminium alloys, to prevent material getting corroded [2]. Hexavalent chromium ions (Hex chrome or Cr6+) were employed under chromate conversion coating till date. Hex chrome is banned due to its carcinogenic and hazard nature by Registration, Evaluation, Authorisation and Restriction of Chemicals (REACH) and Restriction of Hazardous Substance (RoHS) regulation with sunset date of September 2017. Industry and research groups are focused towards replacement of traditional Cr6+ chromating [3]. In this regard, trivalent chromium (Cr3+) ions seem to be the best alternative due to its low toxicity. Moreover, trivalent chromium ions also exhibit good corrosion resistance in tropical environments because most of the launching base of Europe Space Agency (ESA) is located at high humid, high temperature and salty atmosphere [4].

The promising result by $\mathrm{Cr} 3+$ in atmospheric condition is now evaluated under space qualification programs. So, this paper evaluates suitability of trivalent chromium coating in accordance to ASTM and ISO standards. The chromium treatment using trivalent chromium bath containing of zirconium hexafluoride and trivalent chromium salts [5]. In literature, corrosion of coating over AA2024 alloy has been studied in detail. The results indicated that local corrosion starts with development of corrosion rings that evolves hydrogen gas [6]. Most of previous studies are related to corrosion on AA2024 alloy under $\mathrm{SO}_{2}$ atmosphere and surface of corroded area had been analyzed using surface image instruments.

The variation in corrosion inhibition property of Cr3+ among different alloys has not been studied in detail. The NSS conducted over three-alloy surface as mentioned earlier, at the University of Miskolc on salt spray test chamber signifies importance of substrate in coating formation. In present study ICP-OES have been employed to analyze degradation of coated and non-coated aluminium alloy in $0.85 \mathrm{M}$ of $\mathrm{NaCl}$ corrosive solution that is recommended for NSS test by ASTM B117 standard. The work reveals that the trivalent chromium coating (TCC) differs its property from each type alloy which depends on their alloying elements of the base metal. The salt spray showed positive result only for aluminium that has low alloying elements in its elemental constituents.

\section{Experimental Phase}

\subsection{Specimen and Preparation}

The metal samples with the composition as given in Table 1 were obtained as 90 $\times 70 \mathrm{~mm}$ dimension with $4 \mathrm{~mm}$ thick sheets. The received specimens were initially cleaned with detergent and rinsed with isopropyl alcohol, ethanol and acetone for few seconds. The degreased 6063 and 6082 samples were etched with $5 \mathrm{Vol} \% \%$ of $\mathrm{NaOH}$ for $180 \mathrm{~s}$ and desmutted with $\mathrm{H}_{2} \mathrm{SO}_{4}$ solution of $17 \mathrm{v} / \mathrm{v} \%$ for $180 \mathrm{~s}$. Both pre-treatments were carried out at room temperature. In the case of 7075 samples pre-treatments proceeds as follows: 1) etching in $\mathrm{NaOH}$ at $5 \mathrm{Vol} \%$ for $180 \mathrm{~s}$ at $60^{\circ} \mathrm{C}$; 2) desmutting using $50 \mathrm{v} / \mathrm{v} \% \mathrm{H}_{2} \mathrm{SO}_{4}$ for $180 \mathrm{~s}$ at room tem- 
Table 1. Elemental composition of alloy (wt. \%).

\begin{tabular}{ccccccccccccc}
\hline Elements & $\mathrm{Fe}$ & $\mathrm{Si}$ & $\mathrm{Cu}$ & $\mathrm{Mg}$ & $\mathrm{Mn}$ & $\mathrm{Cr}$ & $\mathrm{Ti}$ & $\mathrm{Zn}$ & $\mathrm{Ni}$ & $\mathrm{V}$ & $\mathrm{Ga}$ & $\mathrm{Al}$ \\
\hline $\begin{array}{c}\mathrm{AA} \\
\text { 7075-T651 }\end{array}$ & 0.150 & 0.095 & 1.48 & 2.43 & 0.05 & 0.19 & 0.034 & 5.78 & 0.003 & 0.013 & 0.009 & $90 \%$ \\
$\begin{array}{c}\text { AA } \\
\text { 6082-T651 } \\
\text { AA }\end{array}$ & 0.20 & 1.100 & 0.053 & 0.99 & 0.7 & 0.028 & 0.011 & 0.062 & 0.004 & 0.012 & 0.009 & $97 \%$ \\
6063-T651 & 0.35 & 0.6 & 0.10 & 0.9 & 0.10 & 0.10 & 0.10 & 0.10 & 0.05 & - & - & $98 \%$ \\
\hline
\end{tabular}

perature. All samples were thoroughly rinsed using deionised water after each pre-treatment.

All the three oxide free alloy samples were treated at various immersion times such as $60,120,300$ and 600 secs at $40^{\circ} \mathrm{C}$ using SurTec 650 bath with chemical composition as mention in datasheet [7] under $\mathrm{pH}$ of 3.8 followed by DI (Deionised) water rinsing. After coating, NSS test samples were rinsed with deionised water and dried at room temperature for 24 hours. Coating mass measured on certain samples after three hours drying, as per ISO 3892:2000 standard. The standard insist that samples must immersed in dilute nitric acid for 120 secs to remove deposition of $\mathrm{Cr} 3+$ coating from aluminium alloy. The mass of the samples was measured before and after removal of coating [8]. Some of the samples from coated and non-coated AA7075 were immersed in $0.85 \mathrm{M}$ of $\mathrm{NaCl}$ solution as recommended by ASTM B117 standard for three consecutive days to understand degradation process of trivalent chromium coating and substrate.

\subsection{Salt Spray Test}

The salt spray test is standardized method used to test corrosion resistance of material and surface coating. The ASTM B117 standard for operating salt fog or salt spray cabinet is widely accepted by several space industries including NASA and ESA [9]. This test is operated by placing samples of various size and shape inside the chamber as shown in Figure 1 which is exposed to saline fog or spray that is even distributed among the samples inside B117 testing chamber. The $\mathrm{pH}$ and temperature of salt fog is monitored continuously throughout the test. The samples are examined visually to measure the integrity of alloy coating. Comparisons of pre-and post-testing images under normal photographic picture and visual inspection gives the degradation of samples under salt atmosphere. The variation in salt spray test results highly depends on the type of material to be tested. In case of aluminium alloy if the coated material exhibits any kinds of pits under visual inspection, tested sample are considered as failed per standard mentioned above. The most common tests for aluminium based material is neutral salt spray test which reflects that fact that this type of test solution is prepared to a neutral $\mathrm{pH}$ of 6.5 to 7.2 .

\subsection{ICP-OES}

Inductively Coupled Plasma Optical Emission Spectroscopy is an analytical 


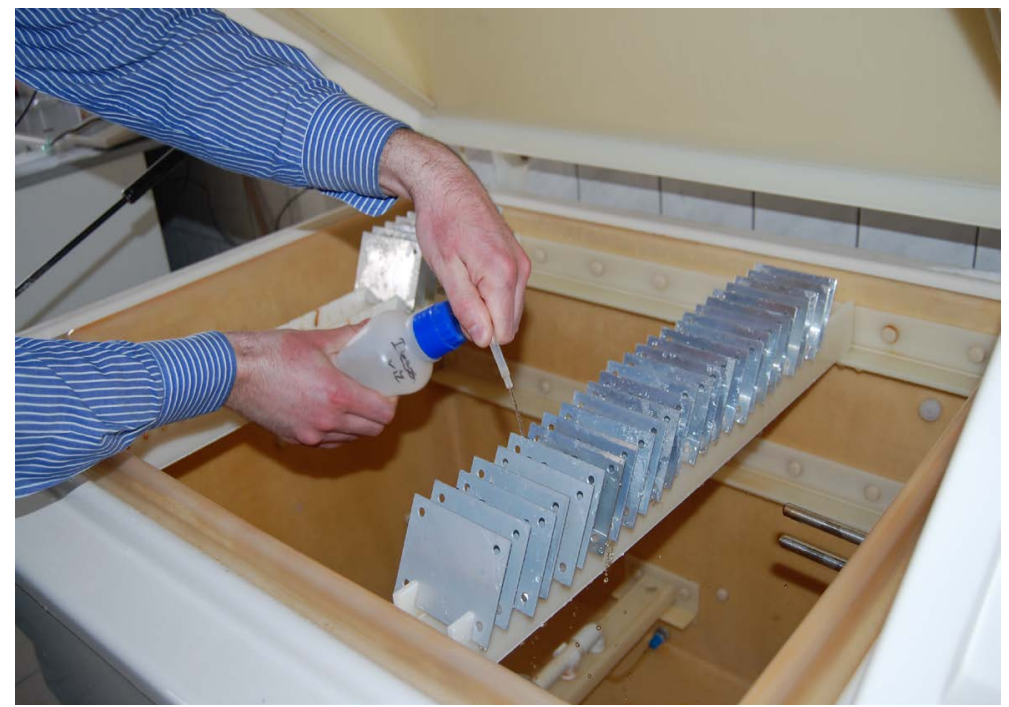

Figure 1. Samples inside salt spray chamber.

technique used for the detection of trace elements. It works on basic principle that the samples at high temperature plasma up to 8000 Kelvin converted to free, excited, or ionized ions. The excited atoms emit radiations when it goes back to ground state. Detectors optically measure the emitted characteristics radiation and intensity [10]. The sample preparation is most important technique that to be considered before any elemental analysis because the solution before test must be free from any impurities to avoid error in detection of elements. To predict behaviour of TCC coating in corrosive liquid the coated sample was immersed in $0.85 \mathrm{M}$ of $\mathrm{NaCl}$ solution for three days in closed condition. The $\mathrm{NaCl}$ solution was prepared form nano pure water supplied by VMR International Kft [11]. The elements inside corrosive liquid from trivalent chromium coating and its substrates is analysed by ICP-OES at department of chemistry in University of Miskolc.

\subsection{Secondary Neutral Mass Spectroscopy (SNMS)}

Elemental depth profile of coatings on various substrates was performed by an INA-X (SPECS Gmbh Berlin) type SNMS system at ATOMKI in Debrecen, Hungary. The device uses an Electron Cyclotron Wave Resonance (ECWR) plasma as an ion source and post ionization medium with sputtering energies of a few $100 \mathrm{eV}$. The SNMS is equipped with a quadrupole type mass spectrometer up to $340 \mathrm{amu}$ for detecting elements. Basically, the samples were bombarded and post ionized using an inductively coupled low pressure radio frequency $\mathrm{Ar}$ discharge. The Ar ions were extracted from the plasma to sputter the sample surface with a high frequency negative bias on the sample. Energy dispersive ion optics discriminated the residual ions. The bombarding energy of Ar ions for TCC coated sample was around $350 \mathrm{eV}$ with plasma pressure of $1.5 \mathrm{mbar}$. The elemental composition of the coating was determined using sensitivity factors of the constituents. The sputtering time was converted into a depth by calibration of sputtering rates with a profilometer and by taking in to account sputtering 
yield changes during profiling and changes in the layer density [12]. The depth scale was fixed by accepting the nominal surface roughness of the sample before and after measurements.

\section{Results and Discussion}

\subsection{Elemental Analysis of Coating}

The SNMS mass spectroscopy analysis of trivalent chromium coating over three different materials as mention earlier shows significant proof that coating consist of similar species independent of substrate on which coating is formed. The mass spectrum graph from SNMS reveals that $\mathrm{Zr}, \mathrm{Cr}, \mathrm{Al}, \mathrm{F}, \mathrm{O}$ atoms are present inside coating that is in accordance with previous work by Manchester group [13] possibly due to usage of the same SurTec 650 solution as shown in Figure 2 In general, elemental analysis of coating can be made by XPS (X-ray Photoelectron Spectroscopy). An XPS analysis published in literature also revealed that coating consist of $\mathrm{AlF}_{3}, \mathrm{Al}_{2} \mathrm{O}_{3}, \mathrm{Cr}(\mathrm{OH})_{3}, \mathrm{ZrO}_{2}$ and $\mathrm{ZrF}_{4}$ species [14].
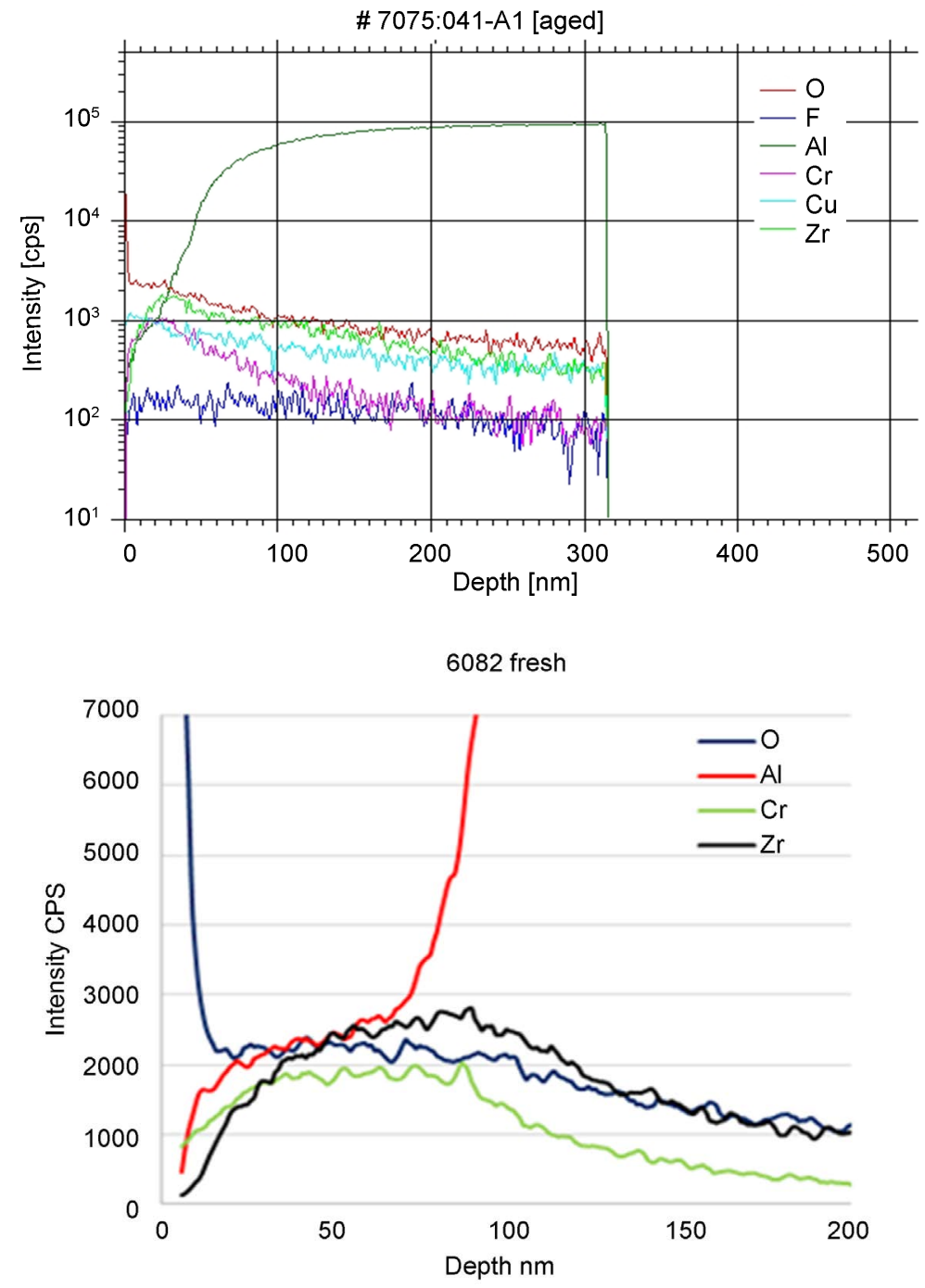

Figure 2. SNMS Elemental analysis of chromate coating. 


\subsection{NSS Test Results}

The following images are the samples of AA7075, AA6063 and AA6082 after salt spray test. The images represent two non-coated (left) and two coated samples (right) with $168 \mathrm{Hrs}$. of exposure time.

The salt spray test result show that AA7075 alloy is not protected by trivalent chromium. The coating over AA6082 and AA6063 seems to have strong bonding towards substrate that is enough to provide corrosion resistance for $168 \mathrm{Hrs}$. in salt spray chamber. However, under same coating condition surface of AA7075 alloy samples is affected by pitting corrosion. Considering AA7075 alloy, it is evident from literature pretreatments that had been used for treating $7 \mathrm{xxx}$ alloy samples is not suitable enough due to its high copper and zinc content. The use of inhibited alkaline solution that is sodium hydroxide is not recommended for high strength alloy like $7 \mathrm{xxx}$ and $2 \mathrm{xxx}$ series alloy in certain aged temper because of the danger of intergranular attack [15]. This is evident from experimental series that $\mathrm{NaOH}$ alkaline solution for removal of aluminium oxide causes more pit formation in comparison with other pretreatment solution. Once sample is taken out from $\mathrm{NaOH}$ bath it turns into brown color that significance presence of copper and zinc content on top of alloy after removal of oxide layer. Inside the bath aluminium oxide layer is completely removed from surface of the alloy and leaves bare metal. Under bath 2 , the $50 \%$ of $\mathrm{H}_{2} \mathrm{SO}_{4}$ solution is not suitable enough for dissolving all the copper ions that were present on surface of alloy sample. Either the sample immersion time or concentration of the solution should have been increased to get optimum result. While considering coating surface morphology of AA7075, it is clear from previous SNMS evaluation that the coating is non-uniform on surface of alloy sample. This non-uniformity of $\mathrm{Cr} 3+$ inside pits and region where copper content is high might be the possible reason for failure of this alloy sample as shown Figure 3. Even though this alloy series is dominated by zinc as a major constituent but only copper ions shows susceptible reason for the failure.

\subsection{Elemental analysis by ICP-OES}

From NSS test (Table 2), only AA 7075 alloy have been selected for the analysis in corrosive liquid.

The elemental analysis Table 3 indicated that almost all elements from coating and substrate is dissolved into strong $\mathrm{NaCl}$ solution.

The formation of bonding between ions inside chromate solution over AA7075 alloy is weak, to withstand concentrated strong base solution. In comparison between zinc and copper, $\mathrm{Cu}$ ions has higher electrode potential as per Table 4 seems to be root cause for breaking of bonds between coating and its substrates. Once copper breaks its bonds followed by other ions inside alloying elements. This can be possible reason for pitting corrosion of AA7075 alloy inside air chamber. The thickness of coating does have much influence on corrosion resistance property of coating because sample exhibit same corrosive state under visual inspection. However, for thick coating number of ions dissolved in 

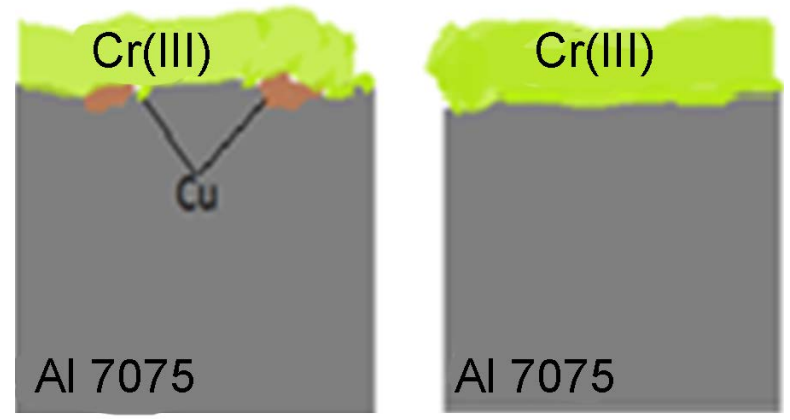

Figure 3. Surface of AA7075 alloy with current pre-treatment with enriched copper ions on surface of aluminium (left) and required TCC for better corrosion protection (right).

Table 2. NSS test result.

\begin{tabular}{ccc}
\hline Alloy & Test Method & Result \\
\hline AA 7075 & 168 Hrs. & Failed after four hours as shown in Figure 4 \\
AA 6063 & 168 Hrs. & Positive no pit formation as shown in Figure 5 \\
AA 6082 & 168 Hrs. & Positive no pit formation as shown in Figure 6 \\
\hline
\end{tabular}

Table 3. Elements detected in corrosive liquid.

\begin{tabular}{cccc}
\hline $\begin{array}{c}\text { Elements } \\
(\mathrm{mg} / \mathrm{liter})\end{array}$ & Non-coated & $\begin{array}{c}\text { Thin coating } \\
\left(0.35 \mathrm{~g} / \mathrm{m}^{2}\right)\end{array}$ & $\begin{array}{c}\text { Thick coating } \\
\left(0.5 \mathrm{~g} / \mathrm{m}^{2}\right)\end{array}$ \\
\hline Aluminium & 117 & 2.17 & 1.71 \\
Zinc & 5.57 & 3.65 & 3.60 \\
Copper & 0.101 & 1.13 & 0.765 \\
Chromium & 0.558 & 0.091 & 0.082 \\
Zirconium & 0.021 & 0.020 & 0.022 \\
Iron & 0.085 & 0.027 & 0.018 \\
Magnesium & 3.97 & 0.565 & 0.495 \\
\hline
\end{tabular}

Table 4. Standard electrode potential of metals in $\mathrm{NaCl}$ solution [16].

\begin{tabular}{ccc}
\hline Metal & $\begin{array}{c}\text { Standard electrode potential for } \\
\text { metal }\end{array}$ & $\begin{array}{c}\text { Corrosion Potential in aerated } 0.5 \mathrm{M} \text { of } \\
\text { NaCl solution } \mathrm{pH}-6\end{array}$ \\
\hline $\mathrm{Mg}$ & $\mathrm{V}$ & $\mathrm{V}$ \\
$\mathrm{Al}$ & -2.37 & -1.40 \\
$\mathrm{Zn}$ & -1.63 & -0.57 \\
$\mathrm{Cr}$ & -0.76 & -0.78 \\
$\mathrm{Fe}$ & -0.74 & -0.11 \\
$\mathrm{Cu}$ & -0.44 & -0.44 \\
\hline
\end{tabular}

$\mathrm{NaCl}$ solution is less compared to thin coating. To achieve coating maximum protection and stabilized structure of coating both ageing and post water immersion technique must be implied applied for this alloy. The ageing is a process 

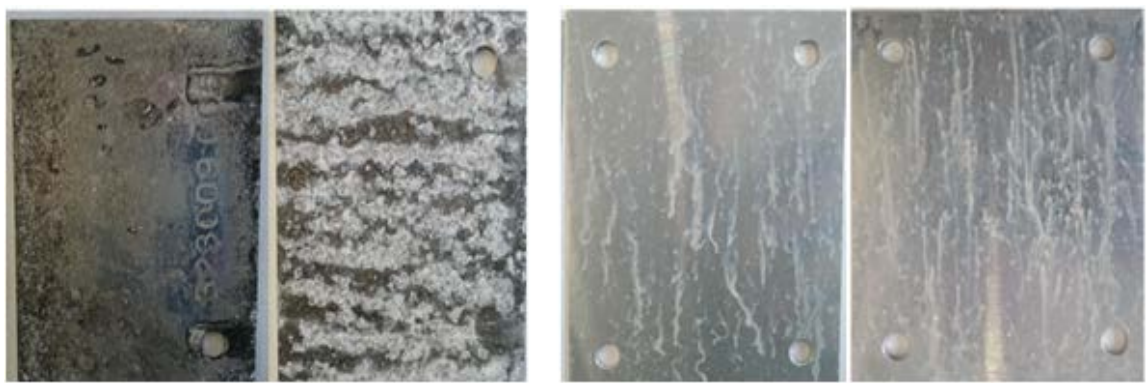

Figure 4. Result of untreated and treated AA7075 alloy with various coating mass $(0.16$ $\left.\mathrm{g} / \mathrm{m}^{2}\right)$ left and $\left(0.36 \mathrm{~g} / \mathrm{m}^{2}\right)$ right.
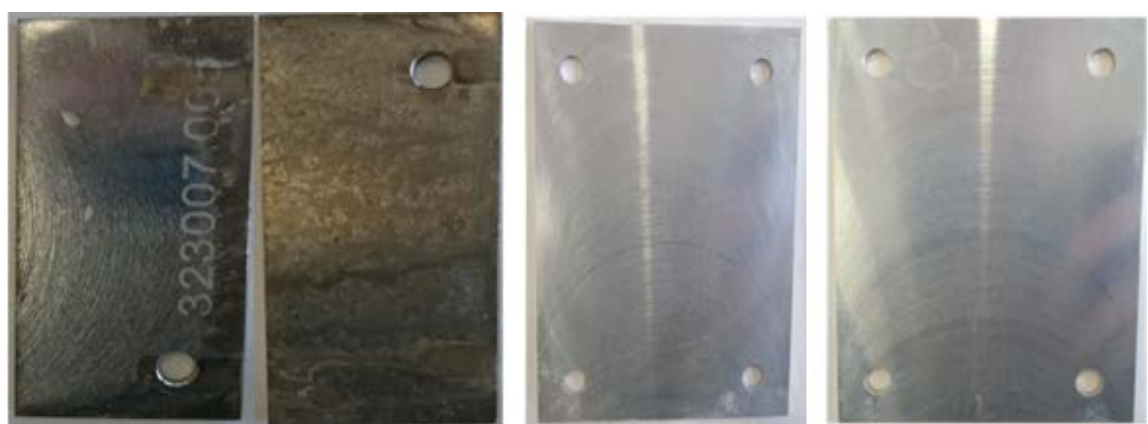

Figure 5. Result of untreated and treated AA6082 alloy with various coating mass $(0.12$ $\left.\mathrm{g} / \mathrm{m}^{2}\right)$ left and $\left(0.46 \mathrm{~g} / \mathrm{m}^{2}\right)$ right.
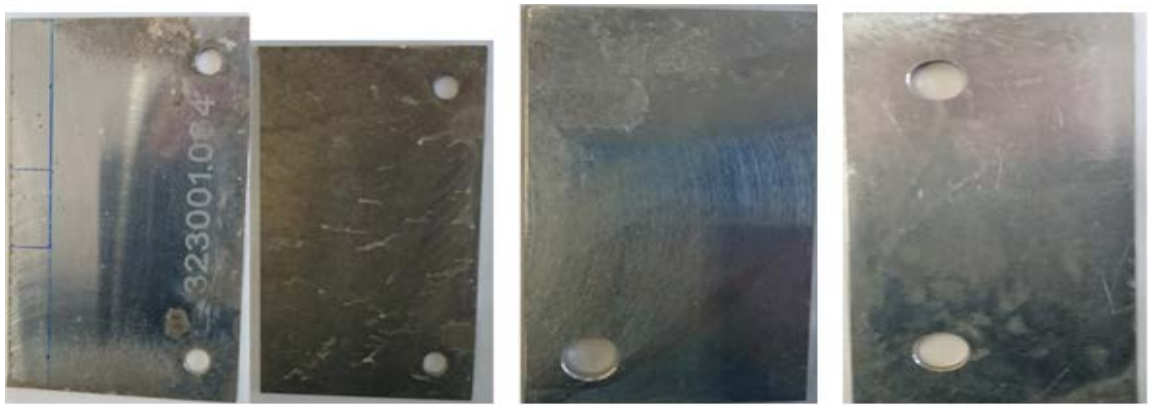

Figure 6. Result of untreated and treated AA6063 alloy with various coating mass $(0.15$ $\left.\mathrm{g} / \mathrm{m}^{2}\right)$ left and $\left(0.3 \mathrm{~g} / \mathrm{m}^{2}\right)$ right.

under which coating is dried for certain period to achieve stabilized structure. Post water treatment is a technique in which freshly coated layer is immersed immediately after sample preparation in to water for few seconds to obtain optimized coating state [17]. The corresponding experimental results will be discussed in our next paper using SNMS technique [18].

\section{Conclusions}

- The trivalent chromium coating is not effective on highly alloyed aluminium, corrosion resistance property of coating on AA7075 alloy is affected by pitting corrosion compared to other two alloys.

- The NSS test result also proves that thickness of the layer does not have any influence corrosion resistance property of trivalent chromium coating. How 
ever, ICP-OES revealed some differences between thin and thick coating films, so there are possibilities for differences, but duration or checking frequency of the salt spray test was not enough.

- The degradation of trivalent chromium coating along with substrate in corrosive liquid by ICP-OES indicated that both coating and substrate are involved in corrosion process.

- The elements dissolved in to salt solution reveals weak bonding of coating towards substrates. The chromium coating over AA7075 alloy has weak bonds compared to AA6063 and AA6082 series. The alloying elements such as zinc and copper are removed from substrate by corrosive solution.

- The copper ions are suspected to be major reason for failure in corrosion resistance of Cr3+ over AA7075 due to high standard electrode potential in $\mathrm{NaCl}$ solution

\section{Acknowledgements}

The authors are thankful to A. Csík and K. Vad (ATOMKI) for the SMNS measurement, furthermore for ICP-OES measurement to O. Bánhidi. This project was financed by ESA, Contract No.4000114580/15/NL/ND.

\section{References}

[1] Davies, J.R. (1993) Associates, Aluminium and Aluminium Alloys. ASM International, ASM World Headquarter, Material Park, Novelty, OH.

[2] Edward, J. (1997) Coating and Surface Treatment System for Metals. ASM International, ASM World Headquarter, Material Park, Novelty, OH.

[3] Official Journal of the European Union (2003) Restriction of the Use of Certain Harzardous Substance in Electrical and Electronic Equipments.

[4] Europe's Spaceport Launchers. 12 May 2004. http://www.esa.int/Our_Activities/Space_Transportation/Europe_s_Spaceport/Euro pe_s_Spaceport2

[5] Guo, Y. and Frankel, G. (2012) Active Corrosion Inhibiton of AA2024-T3 by Trivalent Chrome Process Treatment. Corrosion, 68, 045002-1-045002-10. https://doi.org/10.5006/0010-9312-68-4-3

[6] Glenn, A., Muster, T., Lou, C., Zhou, X., Thompson, G., Boag, A. and Hughes, A. (2011) Corrosion of AA2024-T3 Part III: Propagation. Corrosion Science, 53, 40-50. https://doi.org/10.1016/j.corsci.2010.09.035

[7] SurTec Ltd. (2011) SurTec Technical Datasheet. SurTec International.

[8] European Standards Ltd. (2000) Determination of Coating Mass per Unit Area, ISO 3892:2000. ESA.

[9] NASA (2016) ASTM-B117-16, Standard Practice for Operating Salt Spary Apparatus. NASA.

[10] Franics, R. and Annick, R. (2004) Chemical Analysis: Modern Instrumentation Methods and Techniques. Dunod, John Wiley \& Sons, Ltd.

[11] Chemicals, VMR (2015) Certificate of Analysis. Germany.

[12] Katona, G., Berenyi, Z., Peter, L. and Vad, K. (2008) Depth Profile Analysis of Elec- 
trodeposition Nanoscale Multilayer by SNMS. Vaccum, 82, 270-273.

[13] Skeldon, et al. (2016) Formation of a Trivalent Chromium Conversion Coating on AA2024-T351 Alloy. Journal of Electrochemical Society, 163, C25-C35. https://doi.org/10.1149/2.0771602jes

[14] Qi, J., Hashimato, T., Walton, J., Zhou, X., Skeldon, P. and Thompson, G. (2015) Trivalent Chromium Conversion Coating Formation on Aluminium. Surface and Coating Technology, 280, 317-329.

[15] (1994) ASM Handbook, Surface Engineering. ASM International, ASM World Headquarter, Material Park, Novelty, OH.

[16] Thomas, J. and Hinds, G. (2010) The Electrochemistry of Corrosion.

[17] Li, L. (2013) Corrosion Protection Provided by Trivalent Chromium Process Conversion Coating on Alumimium Alloys. Michigan State University, Michigan.

[18] Thirupathi, K., Bárczy, P., Somosvári, B.M., Vad, K. and Csik, A. (2017) Study of Trivalent Chromate Conversion Coating on Aluminium Alloys by SNMS. ICASS, Journal of Applied Surface Science, Dalian, China.

\section{Submit or recommend next manuscript to SCIRP and we will provide best} service for you:

Accepting pre-submission inquiries through Email, Facebook, LinkedIn, Twitter, etc. A wide selection of journals (inclusive of 9 subjects, more than 200 journals)

Providing 24-hour high-quality service

User-friendly online submission system

Fair and swift peer-review system

Efficient typesetting and proofreading procedure

Display of the result of downloads and visits, as well as the number of cited articles

Maximum dissemination of your research work

Submit your manuscript at: http://papersubmission.scirp.org/

Or contact jsemat@scirp.org 